\title{
Leadership Models and Work Behavior: An Empirical Analysis of Consequences of Authentic and Transformational Leadership
}

\author{
Martin A. Lange and Alina Hernandez-Bark
}

\begin{abstract}
"The greatest leader is not necessarily the one who does the greatest things. He is the one that gets the people to do the greatest things." (Comment by Ronald Reagan, former U.S. President)
\end{abstract}

\begin{abstract}
With increasing importance of organizational effectivity and efficiency measures like Balanced Scorecard and optimization of employee work behavior to achieve higher organizational efficiency, Human Resource activities concerning leadership development and academic leadership research are growing. Throughout the course of the twentieth century, a multitude of empirical studies show primarily positive relationships between different constructs of leadership models and desirable variables of organizational behavior. It becomes apparent, though, that in academic research the selection of analyzed leadership models and their consequences is very heterogeneous. This Master Thesis has the objective to contribute to Leadership Research by applying a comparative empirical study in the-until today-often neglected study population of in-house and sales personnel within the pharmaceutical industry. For this purpose, an online employee survey with $\mathrm{N}=137$ participants from a leading pharmaceutical company in Germany was conducted. Based on contemporary leadership theory, a range of Hypotheses regarding consequences of modern leadership models is empirically tested. The results of the study reconfirm Identification with Manager, Trust \& Loyalty and Employee Satisfaction as consequences of Authentic as well as Transformational leadership. Work context as in-house vs. sales setting shows moderating effects on some of the leadershipconsequences relationships. As the research involves multiple structurally different variables as well as constructs and compares feedback of different study populations, tangible management implications to boost desirable work attitudes and behaviors
\end{abstract}

M. A. Lange $(\square)$

Roche Pharma AG, Grenzach-Wyhlen, Deutschland

A. Hernandez-Bark

Goethe University Frankfurt/Main, Germany Social Psychology Department, CLBO, Frankfurt,

Germany

e-mail: HernandezBark@psych.uni-frankfurt.de

L. Schweizer et al. (eds.), Advances in Pharma Business Management and Research, https://doi.org/10.1007/978-3-030-35918-8_6 
can be derived and appropriately adapted to match the respective work context. Ramifications for future scientific research are also presented.

\section{The Importance of Leadership for Corporate Success}

Today's organizational and business environments become heavily disrupted by challenges stemming from political, economic, social or technological currents and trends. The pharmaceutical industry, for example, faces strains like global, regional or local pressures on product pricing, new Market Access hurdles, compliance guidelines and regulations, competition from innovative, generic or biosimilar companies as well as the advent of digital business models that put corporations under pressure to be effective and efficient. Human Resource (HR) departments evaluate how to best deal with one of the companies' most important resource: their employees. Therefore, leadership is key in organizations' strive for long-term success and financial performance. In order to contribute to leadership research and its positive outcomes for organizations' success, this work's main objective is to provide an overview of relevant leadership theories, to summarize current scientific literature on consequences of leadership and to empirically test relationships between leadership and defined work attitudes and behaviors. A secondary objective is to close research gaps regarding leadership in different work contexts, esp. with regards to pharmaceutical sales and in-house personnel.

\section{The Concept of Leadership}

Burns (1978) stated that "Leadership is one of the most observed, yet least understood, phenomena on earth" (p. 3). This indicates that both the scientific and managerial community operates with various definitions of leadership. Vecchiotti's (2018) chronological perspective of leadership definition development starts with a patriarchic view based on characteristics of men situated in positions of authority. Over time, the role of subordinates was recognized and leadership encourages implementers to contribute to achieve mutually agreed goals. A paradigm shift due to new aspects like collaboration, teamwork, work-life balance, continuous feedback and learning becomes apparent (Vecchiotti 2018). Consequently, the following definition best reflects the latest view: "Leadership is a long-term, value-based process that encourages leaders and implementers to initiate actions that contribute to achieving a common purpose, and to willingly make significant contributions in meeting mutually agreed to goals." (Vecchiotti 2011, p. 6). Leadership, by its processual character, is a construct that has to be considered ambiguous, polymorphic and multifaceted. Von Rostenstiel's Leadership Model (Fig. 1) comprehensively describes the various components and entry points for leadership theory and research (von Rosenstiel 2001). 


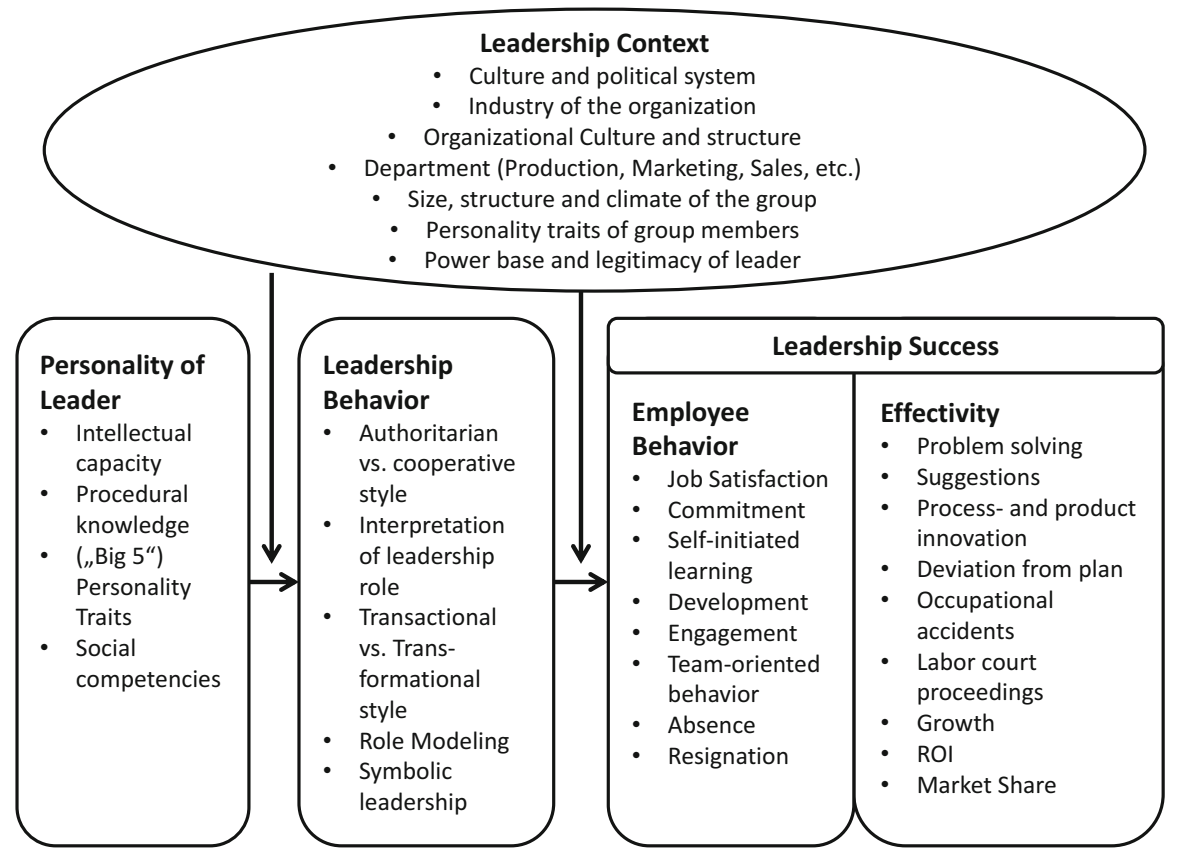

Fig. 1 Von Rostenstiel's Leadership Model. Source: von Rosenstiel (2001)

Von Rosenstiel's Model is an excellent stimulus to look into four different approaches widely discussed: trait approach, behavioral approach, contingency approach, as well as two contemporary approaches of positive leadership.

Historically, leaders were described by traits (Galton and Eysenck 1869). In the 1930s and 1940s, leadership research focused on personal characteristics of an individual and sought to identify personality, social, physical, or intellectual attributes that differentiate leaders from non-leaders. Trait theory was aiming at discovering a built-in set of traits that leaders possess, e.g. "aggressiveness", "self-control", "independence", friendliness", or "optimism" (Owens 1973). A famous example is the "Big 5" Personality Model with the five fundamental dimensions "extraversion", "agreeableness", "conscientiousness", "emotional stability" and "openness to experience" (Costa and McCrae 1992; Norman 1963; Tupes and Christal 1961). Academic research describes "Extraversion" as the most predictive trait of leadership (Bass and Bass 2008).

Behavioral theory tries to identify the right things effective leaders do, e.g. how they communicate, motivate, delegate, plan, or handle meetings (Owens 1973). The most comprehensive example is the Ohio State Studies with the objective to identify independent dimensions of leadership behavior (Schriesheim and Bird 1979). Two key dimensions are "Initiating Structure" and "Consideration". The former describes task-oriented behavior, e.g. putting high emphasis on work organization, work relationships, deadlines and goal attainment. The latter refers to people-oriented 
behavior with a focus on mutual trust, respect for subordinates' ideas, and regard for their feelings (Fleishman and Peters 1962). One of the biggest contribution of behavioral theory is the introduction of five leadership styles: (1) the autocratic leader (who permits little or no freedom, relying on his or her position, knowledge or power to reward and punish), (2) the bureaucratic leader (who gives clear orders, relying on the organization's policies, procedures and rules), (3) the diplomatic leader (who provides limited freedom, relying on personal persuasion), (4) the participative leader (who gives a high degree of freedom and accepts group decisions and majority votes) and (5) the free-reign leader (who lets subordinates operate freely unless asked for invention) (Owens 1973).

Contingency approaches of leadership comprise three elements: (1) a dimension of leader behavior ("x"), (2) a criterion by which the effectiveness of the leader may be determined ("y"), (3) an environmental or situational variable ("z") (Korman 1972). The focus is on the environmental or situational impact " $z$ ", which influences the correlation between " $x$ " and " $y$ ". In the 1960s, Fiedler's Contingency Model is looking for the proper match between a leader's style (i.e. task- vs. relationshiporiented) and the degree to which the situation gives the leader control. If the right match is achieved, effective group performance follows (Fiedler 1977). According to Fiedler's Model, a situation is assessed in terms of three situational dimensions: (1) leader-member relations, (2) task structure, (3) power situation. The combination of these dimensions leads to eight possible categories of leadership situations (Fiedler 1972). Fiedler's fundamental conclusion is to define two ways to improve leader effectiveness: (1) Change of the leader in order to fit the situation, or (2) Change the situation to fit the leader.

Today, two so-called "positive leadership styles" attract high scholarly and managerial attention: Transformational Leadership (TL) and Authentic Leadership (AL). Transformational leaders motivate and encourage others to outperform expectations (Podsakoff et al. 1990). The four components of TL are referred to as the "4 I's": Idealized influence/charismatic leadership, Inspirational motivation, Intellectual stimulation, and Individualized consideration. As TL is associated with performance beyond expectations, this model remains at the forefront of scholarly attention (Bass and Reggio 2006; Gardner et al. 2010; Yaslioglu and Erden 2018). At the beginning of the twenty-first century, authentic leadership gained high scholarly attention and is now among the most prominent leadership styles studied (Banks et al. 2016; Berkovich 2014; Celik et al. 2016; Walumbwa et al. 2008). Walumbwa et al. (2008) define AL as a composite of four dimensions: (1) selfawareness (including an understanding of one's strengths and weaknesses and being cognizant of one's impact on other people), (2) relational transparency (which means presenting one's authentic self to others, sharing information and expressing one's true thoughts and feelings), (3) balanced processing (which means to objectively analyze all relevant data before decision making including challenge deeply held positions), (4) internalized moral perspective (which refers to an integrated form of self-regulation guided by internal moral standards and values versus outside pressures) (Walumbwa et al. 2008). In sum, AL is a construct that incorporates traits, behaviors, styles and skills to promote ethical and honest behavior (Covelli and Mason 2017). 


\section{Constructs and Generation of Hypotheses}

A recent meta-analytic review by Banks et al. (2016) indicates construct redundancy of TL and AL, claiming that none of the constructs adds palpable incremental validity beyond the other. Joo and Nimon (2014) though concluded that both leadership models are complementary, not substitutable (Joo and Nimon 2014). Consequently, it is hypothesized that TL and AL both contribute to the relationship of leadership with various dependent variables by explaining incremental variance.

In line with Zaccaro and Klimoski's (2002) view that different dimensions of organizations can moderate the nature of organizational leadership and its antecedents and consequences (Zaccaro and Klimoski 2002), scientific leadership research has been covering many of these aspects (Golden and Shriner 2017; CharbonnierVoirin et al. 2010; Jensen 2013; Kulophas et al. 2015; Zubair and Kamal 2016). According to Antonakis and Atwater (2002), structural distance can be defined as physical structure (i.e., physical distance between leader and subordinate), organizational structure (e.g., hierarchical level, span of control), and supervision structure (i.e., frequency of leader-subordinate interaction). In this work, research participants' affiliation to a specific organizational setup (in-house vs. sales staff) of the collaborating pharmaceutical company is treated as context variable. Its moderating effect on various leadership-consequences relationships is analyzed. Especially the physical distance between leader and subordinate is structurally different in both work settings. When coming to TL's and AL's relationship with employee attitudinal and behavioral constructs, moderation analysis will be carried out on the basis of participants' affiliation with one of the two work contexts. Moderation hypotheses in this work have the structure presented in Fig. 2 below.

Social Identity Theory (SIT) postulates that individuals identify with social entities, e.g. individuals or organizations, to foster and maintain a positive selfconcept (Tajfel and Turner 1986). Organizations offer employees a multitude of identification targets, so-called foci. These foci can be an organization as a whole, a team, or a manager (van Dick 2001). Positive leadership theories should be able to enhance subordinates' identification with manager (IM). With respect to the IM construct, it is expected that both leadership models will contribute to employees' Identification with Manager:

$\boldsymbol{H}_{\mathbf{1}}$ : Authentic Leadership will be a positive predictor of subordinates' Identification with Manager

$\boldsymbol{H}_{2 \boldsymbol{a}}$ : Transformational Leadership will be a positive predictor of subordinates' Identification with Manager

Moreover, it is hypothesized that the employees' work context (i.e. organizational unit: in-house staff vs. sales) will have a moderating effect on the AL/TL-IM relationship: 


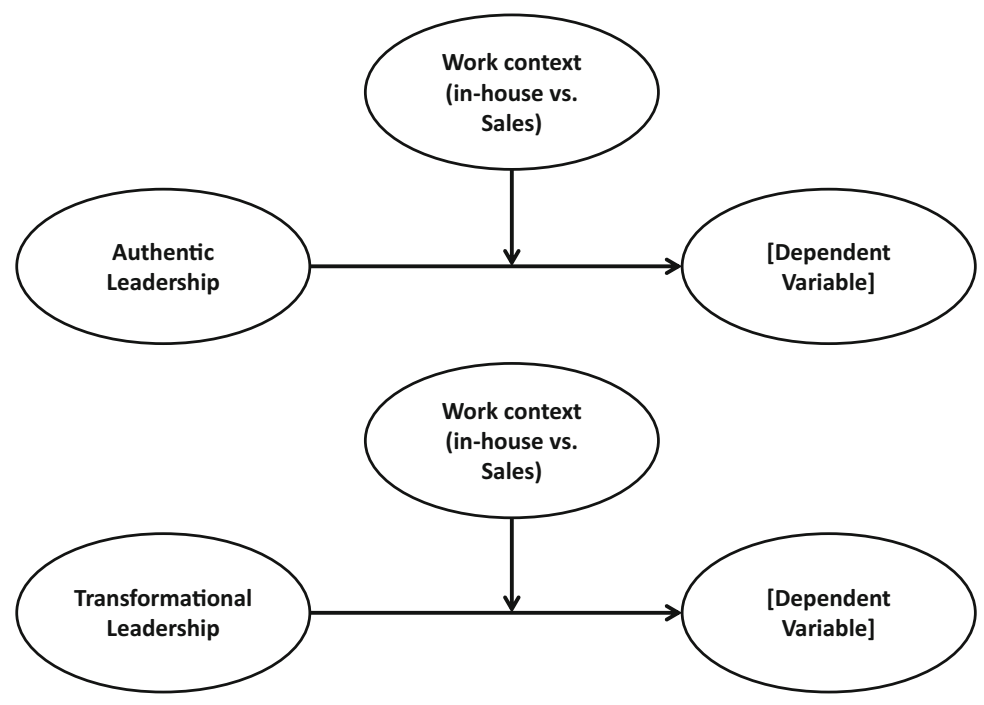

Fig. 2 Structure of hypothesized moderator effects. Source: Own representation

$\boldsymbol{H}_{1 \boldsymbol{b}}$ : The relationship between AL and IM will be moderated by employees' work context (in-house staff vs. sales)

$\boldsymbol{H}_{2 \boldsymbol{b}}$ : The relationship between TL and IM will be moderated by employees' work context (in-house staff vs. sales)

According to West and Farr, Innovative Work Behavior (IWB) describes the intentional creation, introduction and application of new ideas within a work role, group or organization in order to benefit role performance, the group or the organization (West and Farr 1989). In line with previous research, it is expected that both leadership models contribute positively to employees' IWB:

$\boldsymbol{H}_{3 \boldsymbol{a}}$ : Authentic Leadership will be a positive predictor of subordinates' Innovative Work Behavior

$\boldsymbol{H}_{4 \boldsymbol{a}}$ : Transformational Leadership will be a positive predictor of subordinates' Innovative Work Behavior

Moreover, it is postulated that employees' work context, i.e. their affiliation to in-house vs. sales teams, will moderate the AL/TL-IWB relationship:

$\boldsymbol{H}_{3 b}$ : The relationship between AL and IWB will be moderated by employees' work context (in-house staff vs. sales)

$\boldsymbol{H}_{4 \boldsymbol{b}}$ : The relationship between TL and IWB will be moderated by employees' work context (in-house staff vs. sales) 
Rousseau et al. (1998) comprehensively describe the nature of the trust construct: "Trust is a psychological state comprising the intention to accept vulnerability based upon positive expectations of the intentions or behavior of another" (p. 394f). It comprises both exchange processes and an understanding of trust subjects and objects not limited to an individual. For the purpose of this research, focus is on the interpersonal aspect of trust between manager (trust subject) and subordinate (trust object). According to Bass' expansion of Burns' TL theory, loyalty is an outcome of TL, mediated by trust, honesty and further qualities of the leader. This connection is substantiated in recent studies (e.g. Monzani et al. 2016). Overall, both leadership models are hypothesized to positively contribute to employees' Trust and Loyalty (T\&L):

$\boldsymbol{H}_{5 \boldsymbol{a}}$ : Authentic Leadership will be a positive predictor of subordinates' Trust and Loyalty

$\boldsymbol{H}_{\boldsymbol{\sigma} \boldsymbol{a}}$ : Transformational Leadership will be a positive predictor of subordinates' Trust and Loyalty

Again, employees' work context (in-house staff vs. sales team) is expected to moderate the AL/TL-T\&L relationship:

$\boldsymbol{H}_{5 \boldsymbol{b}}$ : The relationship between AL and T\&L will be moderated by employees' work context (in-house staff vs. sales)

$\boldsymbol{H}_{\boldsymbol{b} \boldsymbol{b}}$ : The relationship between TL and T\&L will be moderated by employees' work context (in-house staff vs. sales)

Employee satisfaction (ES) is a construct frequently correlated with leadership in empirical research. Wong and Laschinger (2013), for example, established a direct positive relationship between AL and ES. Yang et al. (2011) confirmed a positive relationship for TL and ES. In this work, a positive relationship between both leadership models and subordinates' ES is postulated:

$\boldsymbol{H}_{7 a}$ : Authentic Leadership will be a positive predictor of subordinates' Employee Satisfaction

$\boldsymbol{H}_{\boldsymbol{8} \boldsymbol{a}}$ : Transformational Leadership will be a positive predictor of subordinates' Employee Satisfaction

Employees' work context (in-house staff vs. sales team) will have a moderating effect on the AL/TL-ES relationship:

$\boldsymbol{H}_{7 \boldsymbol{b}}$ : The relationship between AL and ES will be moderated by employees' work context (in-house staff vs. sales)

$\boldsymbol{H}_{\boldsymbol{8} \boldsymbol{b}}$ : The relationship between TL and ES will be moderated by employees' work context (in-house staff vs. sales) 


\section{Empirical Assessment of the Models}

The statistical software IBM SPSS Statistics 21 including the macro PROCESS (Version 3.1) was used to test the hypotheses (Hayes 2013). In total, 5 hierarchical regression analyses were conducted, consisting out of subsequent, identical steps for each of the five dependent variables. PROCESS Matrix procedure was also chosen to define and analyze the models evaluating moderating effects. Tests of unconditional interactions between independent variables and conditional effects of focal predictors in accordance to values of the moderators are possible.

Data collection for this research project occurred through an online questionnaire activated from June 17th until/including July 15, 2018. Participating functions were employees and their first line managers from selected sales, marketing, market research, market access, medical management, patient care, human resources, communication and further business support teams. $\mathrm{N}=247$ employees, thereof $\mathrm{N}=34$ first line managers, were invited. To avoid respondents' overload, a maximum duration of 15 min per survey is recommended (Batinic and Bosnjak 2000). With an average residence time of a bit longer than 11 min this threshold level was met. $\mathrm{N}=143$ employees clicked through the entire questionnaire. After initial exploratory descriptive data analysis using SPSS, $\mathrm{N}=6$ respondents were excluded due to missing data for four or more constructs. All final data analysis is therefore based on $\mathrm{N}=137$ respondents. Consequently, the ratio of evaluable cases vs. invited employees $(\mathrm{N}=247)$ is $55 \%$. Of $\mathrm{N}=137$ participants, $79(58 \%)$ are female, $58(42 \%)$ are male. The online cohort should quite closely reflect the workforce structure of companies of the healthcare sector. Regarding age distribution, the online cohort matches the national distribution of the German working population very well. An important variable is the affiliation of employees to in-house vs. sales personnel. In our sample, respondents are almost equally split between in-house based $(\mathrm{N}=76 ; 55 \%)$ and sales employees $(\mathrm{N}=61 ; 45 \%)$.

For the operationalization of AL, the ALQ (Authentic Leadership Questionnaire) as a well-established, theory-driven and validated measurement scale was chosen (Walumbwa et al. 2008). For the purpose of this research, a German translation of the ALQ, validated by Peus et al. (2012), was used. The version for external assessment from employees' perspective was applied. Internal consistency alphas (Cronbach's $\alpha$ ) for each of the four subscales and the overall scale were originally reported to be higher than 0.7 in a cross-cultural validation study (Walumbwa et al. 2008). In the present project, SPSS data analysis shows a high Cronbach's $\alpha$ of 0.94 for the overall ALQ construct. Responses were collected on a 5-point Likert scale with pre-determined answer options ranging from (1) "Does not apply at all" to (5) "Fully applies"; German translations were used, respectively.

TL is operationalized by the GTL (Global Transformational Leadership scale). This short measure was tested, validated and confirmed by many studies in various geographical and business contexts (Carless et al. 2000; van Beveren et al. 2017). In the present analysis, Cronbach's $\alpha$ of 0.90 confirms its internal consistency. As in the 
original study, the response format was a 5-point Likert scale ranging from (1) "Does not apply at all" to (5) "Fully applies".

Based on an instrument for Organizational Identification (OI) from Mael and Ashforth (1992), Ullrich et al. (2009) developed a short measure for IM consisting of three items. The original Cronbach's $\alpha$ was .69 (Ullrich et al. 2009). Similar to organizations, teams or workgroups, managers can represent a social category with which employees identify themselves (Gautam et al. 2004). Therefore, the original OI instrument was amended to an IM scale. In the present research, a Cronbach's $\alpha$ of 0.84 was reached. Consistent with the previous measurement constructs, a 5-point Likert scale with identical response options was used.

IWB is assessed by nine items derived from Scott and Bruce's (1994) scale. It has also proven validity and reliability in the work of Janssen (2000). In accordance to the theoretical concept described earlier, three items each refer to the aspects of idea generation, idea promotion and idea realization. Again, a 5-point Likert scale was applied. Response options now ranged from (1) "Never" to (5) "Always". Janssen (2000) reported a Cronbach's $\alpha$ of 0.95 for this instrument. The present data set delivers a very acceptable Cronbach's $\alpha$ of 0.90 .

Trust in and loyalty to the leader is operationalized by use of a six item scale of Podsakoff et al. (1990). The first three items represent the trust component of the instrument. In turn, the remaining three items stand for employees' sense of loyalty to their managers. Again, responses were collected on a 5-point Likert scale with answer options of (1) "Does not apply at all" to (5) "Fully applies". In our data set a Cronbach's $\alpha$ of 0.93 was reached, pointing to a very good internal consistency.

Additional constructs like Organizational Identification (OI) and Employee Satisfaction (ES) considered in the comprehensive work were operationalized by a validated 3-item scale from Mael and Ashforth (1992) and a five-item short instrument based on an original scale developed by Brayfield and Rothe (1951).

Hypotheses $\mathrm{H}_{1 \mathrm{a}}$ to $\mathrm{H}_{8 \mathrm{a}}$ are tested by application of regression analysis. Hierarchical Regression analysis is applied to evaluate the differential explanatory effect of both Leadership Models, AL vs. TL. Four three-step hierarchical regression analyses were run with the following dependent variables: IM, IWB, T\&L and ES. At step one of each of the separate calculations, the demographic variables age and sex were entered to control for covariates. AL was entered at step two as first predictor of conceptual interest. The second predictor TL was entered at step three. The variables were introduced stepwise to see if they have an effect over and above covariates.

Table 1 shows the Means, Standard Deviations, Cronbach's $\alpha$ for all constructs covered, as well as Intercorrelations.

Due to limited space, not all statistical analyses are presented in detail. Of course, all analyses and their results are available when contacting the authors. As age and gender might have effects on the dependent variables of interest, they were entered in the analyses as control variables.

TL explained additional variance above and beyond AL in Identification with the Manager, Trust and Loyalty in the leader, and Employee Satisfaction (confirmation of Hypotheses $\mathrm{H}_{1 \mathrm{a}}, \mathrm{H}_{2 \mathrm{a}}, \mathrm{H}_{5 \mathrm{a}}, \mathrm{H}_{6 \mathrm{a}}, \mathrm{H}_{7 \mathrm{a}}, \mathrm{H}_{8 \mathrm{a}}$ ). However, neither AL nor TL explained 


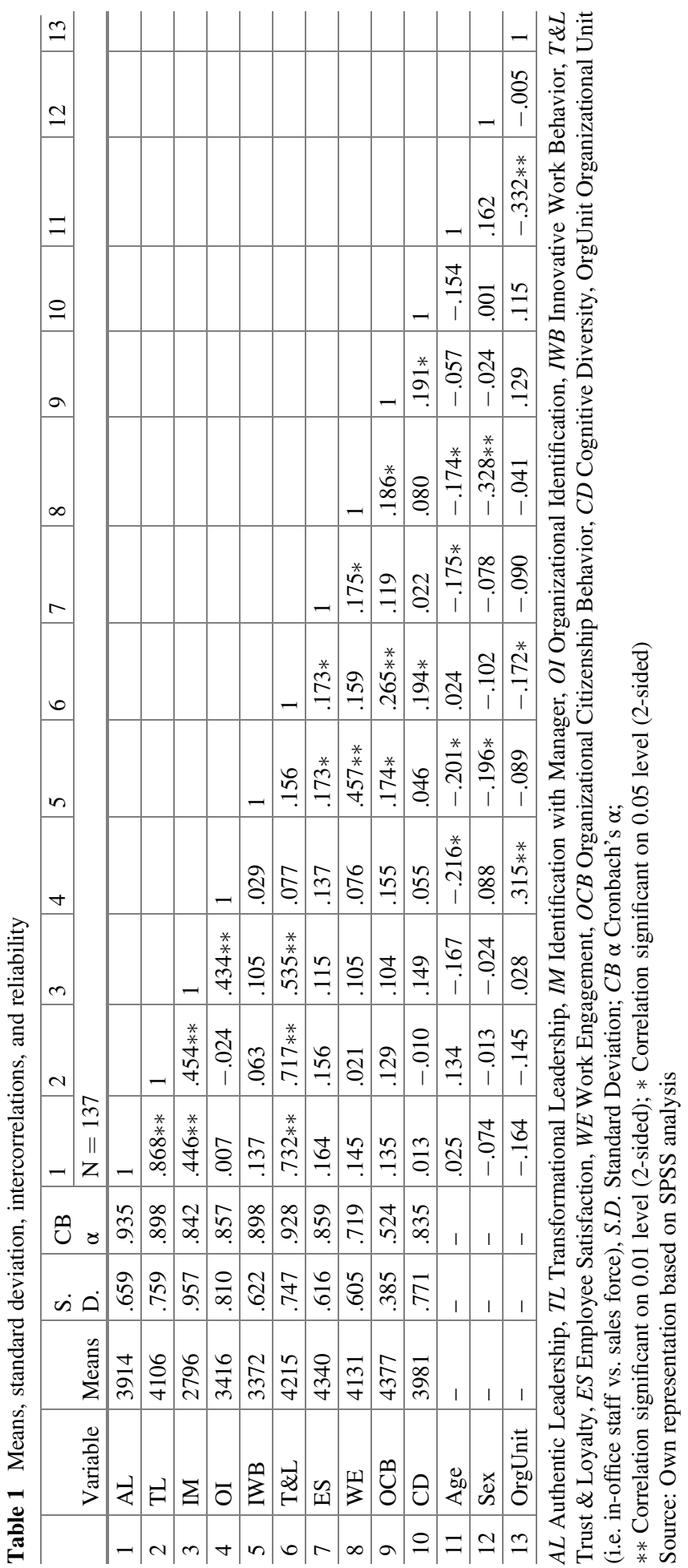




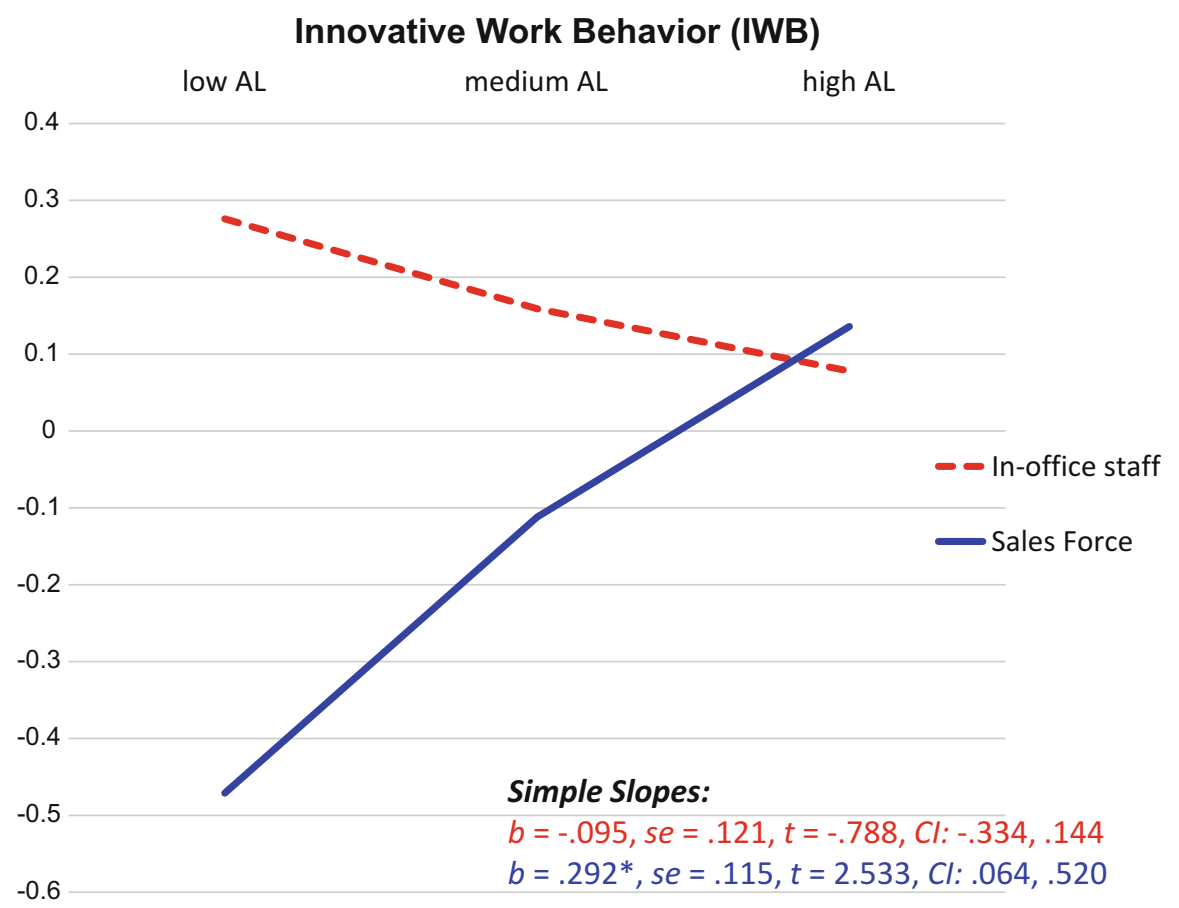

Fig. 3 The moderating influence of work context on the AL-IWB relationship. Source: Own representation based on SPSS analysis

significant variance in Innovative Work Behavior (rejection of Hypotheses $\mathrm{H}_{3 \mathrm{a}}$, $\mathrm{H}_{4 \mathrm{a}}$,).

Nevertheless, when context was included inside the model (moderator: in-house vs. sales), there was a positive relation between AL and innovative work behavior for sales, but not for in-house staff (see Fig. 3). Additionally, the moderator analyses revealed that the relation for both AL and TL and trust and loyalty towards the leader was stronger in sales than in in-house staff (see Figs. 4 and 5). Consequently, hypotheses $\mathrm{H}_{3 \mathrm{~b}}, \mathrm{H}_{5 \mathrm{~b}}, \mathrm{H}_{6 \mathrm{~b}}$ are confirmed. Hypotheses $\mathrm{H}_{4 \mathrm{~b}}$, as well as $\mathrm{H}_{7 \mathrm{~b}}$ and $\mathrm{H}_{8 \mathrm{~b}}$ on moderating influences of context on the relationship between AL/TL and ES are rejected, though.

\section{Summary, Implications and Outlook}

Key objective of this work was to empirically test the relationship between leadership and its key consequences. By means of an online survey with 137 employees of a pharmaceutical company in Germany, the importance of positive leadership models-Authentic and Transformational leadership-for the occurrence of desirable 


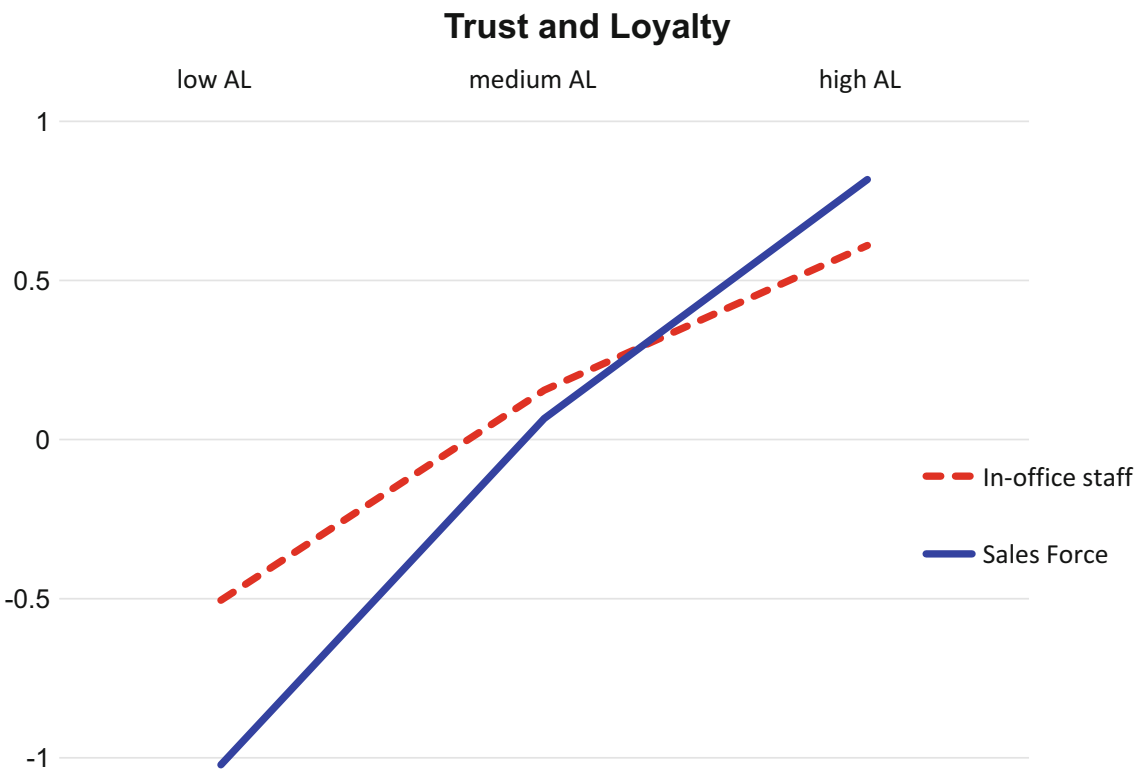

Simple Slopes:

$b=.537 * * *, s e=.085, t=6.303, C l: .368, .706$
$b=.886 * * *, s e=.081, t=10.881, C l: .725,1.047$ $-1.5$

Fig. 4 The moderating influence of work context on the AL-T\&L relationship. Source: Own representation based on SPSS analysis

work attitudes and behaviors like Identification with Manager, Trust and Loyalty, and Employee Satisfaction, was documented. This implies that in corporate practice a positive leadership culture is suitable to stimulate relevant employee actions that contribute significantly to corporate success.

Based on a comprehensive literature review, AL and TL were identified as the main contemporary leadership models of interest. Consequently, these approaches constituted the key independent variables entered both into multiple hierarchical regression as well as moderation analysis models. As a secondary objective, the empirical analysis shed light on the pharmaceutical industry sector and expanded scientific knowledge regarding consequences and potential moderating effects of work contexts.

Essences of the present empirical research are:

- Positive Leadership Behaviors (AL and TL) are positive predictors of critical employee attitudes and business targets like Identification with Manager, subordinates' Trust and Loyalty, and Employee Satisfaction.

- The empirical research results confirm construct validity and conceptual independence of both positive leadership theories, AL and TL. 


\section{Trust and Loyalty}

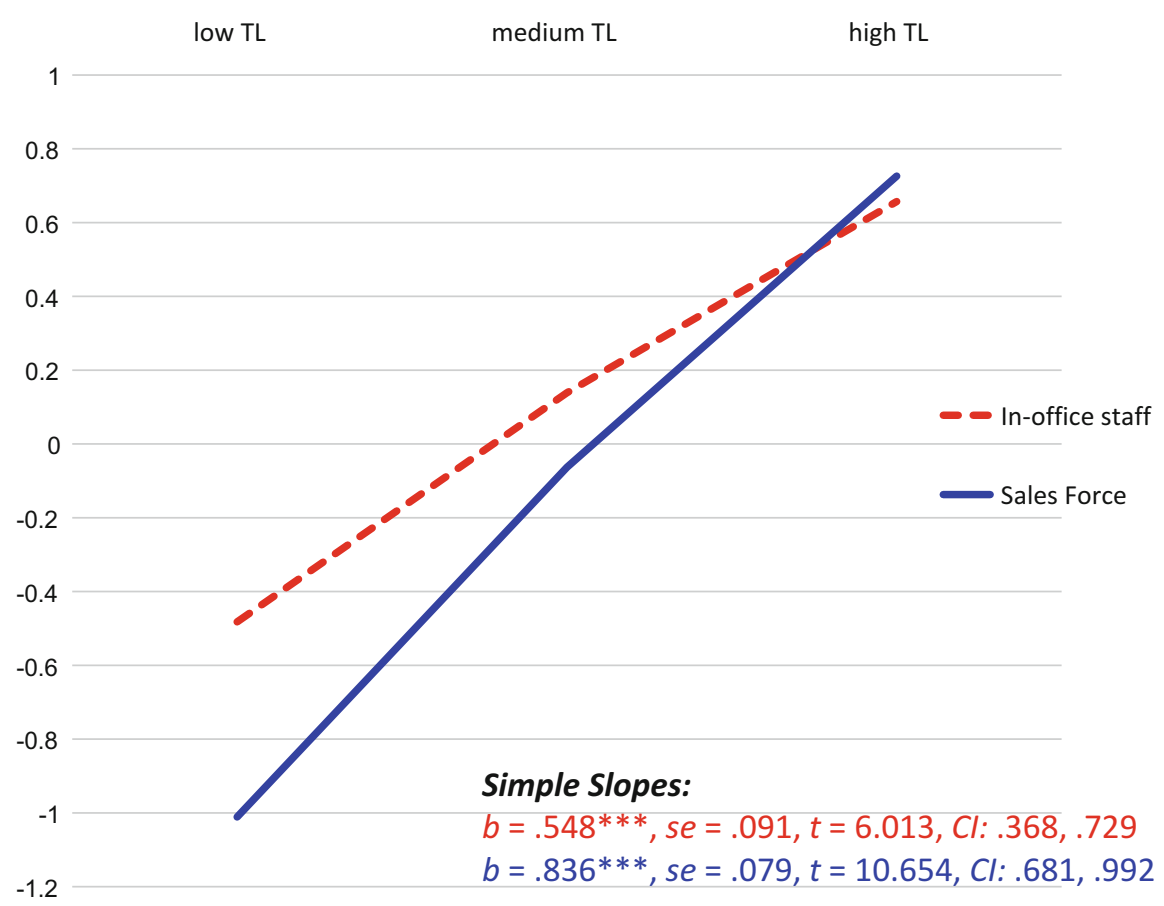

Fig. 5 The moderating influence of work context on the TL-T\&L relationship. Source: Own representation based on SPSS analysis

- Work context, operationalized as in-house vs. sales personnel, significantly impact some leadership-consequences relationships, i.e. leadership's relationship with Trust and Loyalty is significantly moderated by work context (with a stronger effect in the study population of sales force); for the AL-IWB relationship, a significant moderating effect for sales personnel was also confirmed.

Although an often stated need for quantification of positive leadership behavior in corporate financial success and target figures was not subject of this investigation, the confirmed relationships between positive leadership and most of the desirable work attitudes and behaviors indicate that $\mathrm{AL}$ and TL contribute positively to operating profit.

In addition to the above mentioned financial aspects, hints on positive aspects of employee behavior, namely Innovative Work Behavior, could be derived. As this was especially accentuated in the context of customer facing sales personnel, one could infer that high AL in sales contexts can have a halo effect on sales reps customer interactions.

In order to achieve corporate goals, a recommendation to pharmaceutical companies is to establish a corporate culture that fosters positive leadership behavior. 
Leader recruitment, leadership training and development should take the "4 I's" of $\mathrm{TL}$ and the four aspects of AL as a reference. Specific examples for HR departments can be to provide platforms and trainings for people managers to develop capabilities as mentors, coaches and active listeners. In order to be able to act as a positive role model for employees, leaders should be clear about ethical and moral standards, also with regards to the specifics of the pharmaceutical industry. Moreover, tools to foster leaders' and employees' self-awareness, a culture that supports transparency and one of error tolerance would be very beneficial to establish the desirable leadership styles, hence positive employee attitudes and behaviors.

Although this research shows promising results, a few limitations need to be mentioned. First, this study has a cross-sectional design. Therefore, longitudinal investigations could be of interest in order to evaluate intrapersonal developments over time and if and how they impact job attitudes and behavior. Second, due to requirements of the collaborating company's works council in order to ensure anonymity and maximum data protection, a dyadic approach to collect and analyze data based on team structures was not allowed. It would be advisable for future research to collect and use this information in order to enhance data quality and model reliability by reducing a potentially high amount of additional variance. Similarly, the actual duration of individual leader-subordinate relationships could actively be controlled for, as interpersonal relationships including the development of trust tend to evolve over time. Third, all outcome variables are solely based on employee self-assessment. This potential for common source bias could be reduced in future studies if additional sources of feedback and information can be taken into account, e.g. supervisors' evaluations of employees' behavior or secondary data from more objective performance evaluations. Fourth, the present moderation analysis is purely based on self-reported organizational allocation to in-house vs. sales departments. This was used as a surrogate for work context, primarily reflecting physical distance to the supervisor, which in turn was supposed to impact frequency and quality of communication. However, quality of leader-subordinate interaction might be perceived quite differently on a personal level. In future studies, analysis could therefore be controlled for effective communication frequency and/or perceived quality of communication channel and content of leader-subordinate exchange.

Despite these limitations and implications for future research, the study provided various important insights. It seems to be first research project to systematically analyze the two contemporary positive leadership models Authentic Leadership and Transformational Leadership in a comparative context of in-house staff and sales representatives of a single pharmaceutical company in Germany.

In order to build on the current outcomes, the following direction for future research can be proposed. First, a longitudinal study design could be chosen to be able to track the development of interpersonal leader-subordinate relationships over time. Second, recourse to potentially more objective multi-source data to substantiate the expressed employee attitudes and behaviors might be beneficial. Third, the study could be run in or across different companies and industries to detect significant differences or communalities. Similarly, the study could be replicated by 
inclusion of different hierarchy levels within companies to assess if team size or span of control impacts the relationship of leadership and its consequences. Fourth, the evaluation of antecedents of AL and TL could be added to the research design to potentially derive implications for people management and personnel development.

\section{References}

Antonakis, J., \& Atwater, L. (2002). Leader distance: A review and a proposed theory. The Leadership Quarterly Annual Review, 13(6), 673-704. https://doi.org/10.1016/S10489843(02)00155-8.

Banks, G. C., McCauley, K. D., Gardner, W. L., \& Guler, C. E. (2016). A meta-analytic review of authentic and transformational leadership: A test for redundancy. The Leadership Quarterly, 27, 634-652. https://doi.org/10.1016/j.leaqua.2016.02.006.

Bass, B., \& Bass, R. (2008). The Bass handbook of leadership: Theory, research, and managerial applications. New York, NY: Free Press.

Bass, B. M., \& Reggio, R. E. (2006). Transformational leadership. Mahwah, NJ: Erlbaum.

Batinic, B., \& Bosnjak, M. (2000). Fragebogenuntersuchungen im Internet. In B. Batinic (Ed.), Internet für Psychologen (2nd ed., pp. 287-317). Göttingen/Bern: Hogrefe.

Berkovich, I. (2014). Between person and person - Dialogical pedagogy in authentic leadership development. Academy of Management Learning \& Education, 13(2), 245-264. https://doi.org/ 10.5465/amle.2012.0367.

Brayfield, A. H., \& Rothe, H. F. (1951). An index of job satisfaction. Journal of Applied Psychology, 35, 307-311.

Burns, J. M. (1978). Leadership. New York, NY: Harper \& Row.

Carless, S. A., Wearing, A. J., \& Mann, L. (2000). A short measure of transformational leadership. Journal of Business \& Psychology, 14(3), 389-406. Retrieved from http://www.jstor.org.proxy. ub.uni-frankfurt.de/stable/25077344.

Celik, A., Akgemci, T., \& Akyazi, T. E. (2016). A comparison between the styles of transformational leaders and authentic leaders in crisis management. International Journal of Academic Research in Business and Social Sciences, 6(2), 183-196.

Charbonnier-Voirin, A., Assâad, E. A., \& Vandenberghe, C. (2010). A multilevel model of transformational leadership and adaptive performance and the moderating role of climate for innovation. Group \& Organization Management, 35(6), 699-726. https://doi.org/10.1177/ 1059601110390833.

Costa, P. T., Jr., \& McCrae, R. R. (1992). Revised NEO personality inventory. Odessa, FL: Psychological Assessment Resources.

Covelli, B. J., \& Mason, I. (2017). Linking theory to practice: Authentic leadership. Academy of Strategic Management Journal, 16(3), 1-10.

Fiedler, F. E. (1972). The effects of leadership training and experience: A contingency model interpretation. Administrative Science Quarterly, 17(4), 453-470.

Fiedler, F. E. (1977). Job engineering for effective leadership: A new approach. Management Review, 66(9), 29-31.

Fleishman, E. A., \& Peters, D. R. (1962). Interpersonal values, leadership attitudes and managerial success. Personnel Psychology, 15(2), 127-143. https://doi.org/10.1111/j.1744-6570.1962. tb01855.x.

Galton, F. / Eysenck, H. J. (1869). Hereditary genius. London: Macmillan.

Gardner, W. L., Lowe, K. B., Moss, T. W., Mahoney, K. T., \& Cogliser, C. C. (2010). Scholarly leadership of the study of leadership: A review of the leadership quarterly's second decade, 2000-2009. The Leadership Quarterly, 21(6), 922-958. https://doi.org/10.1016/j.leaqua.2010. 10.003 . 
Gautam, T., van Dick, R., \& Wagner, U. (2004). Organizational identification and organizational commitment: Distinct aspects of two related concepts. Asian Journal of Social Psychology, 7, 301-315. https://doi.org/10.1111/j.1467-839X.2004.00150.x.

Golden, J. H., \& Shriner, M. (2017). Examining relationships between transformational leadership and employee creative performance: The moderator effects of organizational culture. The Journal of Creative Behavior, 1-14. https://doi.org/10.1002/jocb.216.

Hayes, A. F. (2013). Introduction to mediation, moderation, and conditional process analysis: A regression-based approach. New York, NY: Guilford Press.

Janssen, O. (2000). Job demands, perceptions of effort-reward fairness and innovative work behavior. Journal of Occupational and Organizational Psychology, 73, 287-302.

Jensen, U. T. (2013). Transformational leadership and performance in public service organizations: An investigation of employee motivation as mediator and person-organization fit and leaderemployee distance as moderators. Paper presented at International research conference: One step beyond - refining public service motivation theory and research methods, Utrecht, 14/11/ 2013-16/11/2013.

Joo, B., \& Nimon, K. (2014). Two of a kind? A canonical correlational study of transformational leadership and authentic leadership. European Journal of Training and Development, 38(6), 570-587. https://doi.org/10.1108/EJTD-12-2013-0129.

Korman, A. K. (1972). Applications of management theory: A review of the empirical literature and a new direction. Academy of Management Proceedings, 170-173. https://doi.org/10.5465/ AMBPP.1972.4981433.

Kulophas, D., Ruengtrakul, A., \& Wongwanich, S. (2015). The relationships among authentic leadership, teachers' work engagement, academic optimism and school size as moderator: A conceptual model. Procedia - Social and Behavioral Sciences, 191, 2554-2558. https://doi.org/ 10.1016/j.sbspro.2015.04.298.

Mael, F., \& Ashforth, B. E. (1992). Alumni and their Alma mater: A partial test of the reformulated model of organizational identification. Journal of Organizational Behavior, 13(2), 103-123. Retrieved from http://www.jstor.org.proxy.ub.uni-frankfurt.de/stable/2488176.

Monzani, L., Braun, S., \& Van Dick, R. (2016). It takes two (or three) to tango: The interactive effect of authentic leadership and organizational identification on employee silence intentions. Zeitschrift für Personalforschung / German Journal of Research in Human Resource Management, 30, 246-266. https://doi.org/10.1177/2397002216649896.

Norman, W. T. (1963). Toward an adequate taxonomy of personality attributes: Replicated factor structure in peer nomination personality ratings. Journal of Abnormal Psychology, 66, 574-583. https://doi.org/10.1037/h0040291.

Owens, J. (1973). What kind of leader do they follow? Management Review, 62(4), 54-57. University of Michigan.

Peus, C., Wesche, J. S., Streicher, B., Braun, S., \& Frey, D. (2012). Authentic leadership: An empirical test of its antecedents, consequences, and mediating mechanisms. Journal of Business Ethics, 107, 331-348. Retrieved from http://www.jstor.org.proxy.ub.uni-frankfurt.de/stable/ 41476253.

Podsakoff, P. M., MacKenzie, S. B., Moorman, R. H., \& Fetter, R. (1990). Transformational leader behaviors and their effects on followers' trust in leader, satisfaction and organizational citizenship behaviors. Leadership Quarterly, 1, 107-142. https://doi.org/10.1016/1048-9843(90) 90009-7.

Rousseau, D. M., Sitkin, S. B., Burt, R. S., \& Camerer, C. (1998). Not so different after all: A crossdiscipline view of trust. Academy of Management Review, 23(3), 393-404.

Schriesheim, C. A., \& Bird, B. J. (1979). Contributions of the Ohio state studies to the field of leadership. Journal of Management, 5(2), 135-145. https://doi.org/10.1177/ 014920637900500204.

Scott, S. G., \& Bruce, R. A. (1994). Determinants of innovative behavior: A path model of individual innovation in the workplace. Academy of Management Journal, 37(3), 580-607.

Tajfel, H., \& Turner, J. C. (1986). The social identity theory of intergroup behavior. Psychology of Intergroup Relations, 5, 7-24. 
Tupes, E. C. \& Christal, R. E. (1961). Recurrent personality factors based on trait ratings (Technical Report ASD-TR-61-97). Lackland Air Force Base, TX: U.S. Air Force. Retrieved from http:// www.dtic.mil.proxy.ub.uni-frankfurt.de/dtic/tr/fulltext/u2/267778.pdf

Ullrich, J., Christ, O., \& van Dick, R. (2009). Substitutes for procedural fairness: Prototypical leaders are endorsed whether they are fair or not. Journal of Applied Psychology, 94, 235-244. https://doi.org/10.1037/a0012936.

van Beveren, P., Dórdio Dimas, I., Lourenco, P. R., \& Rebelo, T. (2017). Psycho metric properties of the Portuguese version of the global transformational leadership (GTL) scale. Journal of Work and Organizational Psychology, 33(2), 109-114. https://doi.org/10.1016/j.rpto.2017.02. 004.

van Dick, R. (2001). Identification in organizational contexts: Linking theory and research from social and organizational psychology. International Journal of Management Reviews, 3(4), 265-283.

Vecchiotti, R. (2011). Leadership: A contemporary view. Retrieved from https://beampines. wordpress.com/2011/03/10/leadership-a-contemporary-view/

Vecchiotti, R. (2018). Contemporary leadership: The perspective of a practitioner. Journal of Leadership Studies. https://doi.org/10.1002/jls.21573.

von Rosenstiel, L. (2001). Führung. In H. Schuler (Ed.), Lehrbuch der Personalpsychologie (pp. 317-346). Göttingen: Hogrefe.

Walumbwa, F. O., Avolio, B. J., Gardner, W. L., Wernsing, T. S., \& Peterson, S. J. (2008). Authentic leadership: Development and validation of a theory-based measure. Journal of Management, 34(1), 89-126. https://doi.org/10.1177/0149206307308913.

West, M. A., \& Farr, J. L. (1989). Innovation at work: Psychological perspectives. Social Behavior, 4(1), 15-30. Retrieved from http://eprints.lancs.ac.uk/id/eprint/63023.

Wong, C. A., \& Laschinger, H. K. (2013). Authentic leadership, performance, and job satisfaction: The mediating role of empowerment. Journal of Advanced Nursing, 69(4), 947-959. https://doi. org/10.1111/j.1365-2648.2012.06089.x.

Yang, F.-H., Wu, M., Chang, C.-C., \& Chien, Y. (2011). Elucidating the relationships among transformational leadership, job satisfaction, commitment foci and commitment bases in the public sector. Public Personnel Management, 40(3), 265-278.

Yaslioglu, M. M., \& Erden, N. S. (2018). Transformational leaders in action: Theory has been there, but what about practice? The IUP Journal of Business Strategy, 15(1), 42-53.

Zaccaro, S. J., \& Klimoski, R. (2002). The Interface of leadership and team processes. Group \& Organization Management, 27(1), 4-13. https://doi.org/10.1177/1059601102027001002.

Zubair, A., \& Kamal, A. (2016). Perceived authentic leadership, work-related flow, and creative work behavior: Moderating role of organizational structures. Journal of Social Sciences, 9(2), 426-441.

Open Access This chapter is licensed under the terms of the Creative Commons Attribution 4.0 International License (http://creativecommons.org/licenses/by/4.0/), which permits use, sharing, adaptation, distribution and reproduction in any medium or format, as long as you give appropriate credit to the original author(s) and the source, provide a link to the Creative Commons licence and indicate if changes were made.

The images or other third party material in this chapter are included in the chapter's Creative Commons licence, unless indicated otherwise in a credit line to the material. If material is not included in the chapter's Creative Commons licence and your intended use is not permitted by statutory regulation or exceeds the permitted use, you will need to obtain permission directly from the copyright holder.

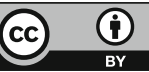

